\title{
Wpływ współczynnika wypełnienia drutów proszkowych z rdzeniem metalicznym na wydajność i stabilność procesu spawania
}

\author{
The influence of fill ratio \\ in metal cored electrodes \\ on efficiency and stability of welding process
}

\section{Streszczenie}

Praca badawcza powstała na kanwie współpracy pomiędzy Multimet Sp. z o.o. a Politechniką Wrocławską. Przedmiotem badań była ewaluacja wpływu współczynnika wypełnienia drutów proszkowych z rdzeniem metalicznym na wydajność oraz stabilność procesu spawania. W treści przedstawiono jak istotny jest wpływ tego parametru na charakterystykę procesu. Wpływ natężenia prądu spawania na wydajność stapiania dla drutów proszkowych o współczynniku wypełnienia 17 i $20 \%$ został zilustrowany wykresem. Na jego podstawie określono wartość natężenia prądu, dla którego bez względu na rodzaj użytego drutu, wydajność jest taka sama. Wykonano próby mające na celu określenie stabilności jarzenia się łuku dla natężenia prądu o wartości 152 A i 369 A.

Słowa kluczowe: druty proszkowe; współczynnik wypełnienia; wydajność; stabilność

\begin{abstract}
Research work is a result of collaboration between Multimet sp.z.o.o and the Wrocław University of Science and Technology. The work deals with the influence of the fill ratio of metal cored electrodes. The text shows the importance of the influence of this parameter on the efficiency and stability of the welding process for selected welding parameters. The influence of welding current on the efficiency of welding with metal cored electrodes for the fill ratio of 17 and $20 \%$ is illustrated in the graph. On its basis welding current, for which efficiency of both types of metal cored electrodes is the same was specified. Tests were carried out to determine the stability of arcing for the welding current $152 \mathrm{~A}$ and $369 \mathrm{~A}$.
\end{abstract}

Keywords: metal cored electrode; fill ratio; efficiency; stability

\section{Wstęp}

Druty proszkowe stosowane są od wielu lat w procesach przemysłowych. Wśród nich należy wymienić na przykład spawalnictwo i napawanie $[1,2]$. W spawalnictwie znajdują one zastosowanie w łączeniu stali niskostopowych i drobnoziarnistych (PN-EN ISO 17632:2016-02), stali o wysokiej wytrzymałości (PN-EN ISO 18276:2008), stali odpornych na pełzanie (PN-EN ISO 17634:201510), stali nierdzewnych i żaroodpornych (PN-EN ISO 17633:2010) czy żeliwa (PN-EN ISO 1071:2016-02). Druty te zbudowane są z metalowej osłony rurkowej wykonanej ze stali oraz rdzenia (wypełnienia) rutylowego, zasadowego bądź metalicznego. Do pracy badawczej został wybrany drut o rdzeniu metalicznym z racji uniwersalności aplikacji i istniejących badaniach z wykorzystaniem drutu o zbliżonych właściwościach i parametrach [2]. Rdzeń tych drutów składa się z proszku żelaza oraz proszków innych metali i niemetalicznych mających działanie na przykład utleniające. Druty te najczęściej stosuje się do spawania niestopowych i niskostopowych stali konstrukcyjnych. Istnieje wiele możliwości wykonania szwu (miejsca styku krawędzi blachy) w celu zamknięcia przekroju drutu. Najczęściej stosowaną metodą łączenia krawędzi metalowej rurki jest ich zgrzewanie lub zagięcie [3]. Jednak najnowocześniejszą oraz zapewniającą największą pewność i jakości jest wykonanie zamknięcia przez spawanie szwu wiązką lasera. Jest to efekt precyzyjnego, kontrolowanego procesu o niskiej energii liniowej.

Materiały dodatkowe do spawania otrzymywane tą metodą nazywane są bezszwowymi drutami proszkowymi. Cechuje je szereg zalet. Wśród nich należy wyróżnić:

Mgr inż. Katarzyna Żegleń - Politechnika Wrocławska; inż. Mateusz Kurasiak, mgr inż. Karol Procelewski, mgr inż. Grzegorz Całek - Multimet Sp. z o.o.

Autor korespondencyjny/Corresponding author. katarzyna.zeglen@pwr.edu.pl 
wysoką stabilność formy drutu, doskonałe podawanie, stabilność łuku, która determinuje małą ilość rozprysków, brak konieczności suszenia przed użyciem, wysoką wydajność w porównaniu z drutami litymi, niską zawartość wodoru poniżej $5 \mathrm{ml} / 100 \mathrm{~g}$ zapewniającą odporność na pękanie zimne. Pokrycie powierzchni drutu miedzią zapewnia dobrą przewodność prądu elektrycznego oraz zapobiega powstawaniu korozji.

W przemyśle współczynnik wypełnienia jest definiowany $w$ różny sposób. Wybór odpowiedniej definicji zależy na przykład od etapu produkcji, na którym jest konieczność jego wyznaczenia. Zazwyczaj, do jego opisu wykorzystuje się stosunek masy proszku (rdzenia drutu) do całkowitej masy drutu $(1)[3,4]$. Zależność tą stosuje się przy określaniu współczynnika wypełnienia dla produktu gotowego.

$$
\text { współczynnik wypełnienia }=\frac{\text { masa rdzenia }}{\text { masa drutu }}
$$

Wartość współczynnika wypełnienia ma znaczący wpływ na przebieg procesu spawania. Wysoki współczynnik w przypadku drutów rutylowych i zasadowych ma korzystny wpływ, w przeciwieństwie do drutów metalicznych. Druty o rdzeniu metalicznym podczas spawania zaczynają zachowywać się jak druty lite. Druty o wysokim współczynniku wypełnienia wymagają wysokiej energii potrzebnej do ich stopienia. W konsekwencji, mniejszy udział energii jest wykorzystywany do penetracji w materiał spawany.

W drutach proszkowych prąd jest transferowany przez koszulkę rurkową drutu wykonaną ze stali [4]. Im wyższy współczynnik wypełnienia drutu, tym przekrój poprzeczny rurki metalowej jest mniejszy. W związku ze zmniejszeniem pola przekroju poprzecznego metalowej rurki, wzrasta gęstość prądu, a co za tym idzie również wydajność stapiania. Współczynnik stapiania jest zależny od takich parametrów jak prędkość podawania drutu oraz średnica drutu [4].

Celem badań było określenie jaki wpływ na stabilność procesu spawania ma współczynnik wypełnienia. Pośród wielu badań stosowanych w próbie spawalności wybrano określenie zdolności stabilnego jarzenia się łuku spawalniczego [5].

\section{Materiały i metody}

Do badań pozwalających na określenie wydajności i stabilności procesu spawania zastosowano dwa druty proszkowe metaliczne gatunku EN ISO 17632-A-T 46 6 M M 1 H5 o średnicy 1,2 mm i różnym współczynniku wypełnienia. Rysunek 1 przedstawia drut o współczynniku wypełnienia $17 \%$, a rysunek 2 drut o współczynniku wypełnienia $20 \%$. Współczynniki zostały wyliczone na podstawie zależności uwzględniającej stosunek masy proszku do masy całego drutu (1). Wybrane druty proszkowe o rdzeniu metalicznym są klasyfikowane według granicy plastyczności i energii łamania. Wykazują minimalną granicę plastyczności o wartości $460 \mathrm{MPa}$ oraz udarność spoiwa o wartości 47J spełnionej lub przekraczającej tą wielkość w temperaturze $-60{ }^{\circ} \mathrm{C}$. Procenty frakcji masowej to: mangan $(2,0 \%)$, chrom $(0,2 \%)$, nikiel $(0,5 \%)$, molibden $(0,2 \%)$, wanad $(0,08 \%)$, niob $(0,05 \%)$ i miedź $(0,3 \%)$.

Wydajność stapiania była wyznaczana wagowo. Szpula materiału dodatkowego była ważona przed i po spawaniu. Stałym parametrami i czynnikami były: średnica drutu, prąd, rozdaj prądu i biegunowość, prędkość spawania i przepływ gazu. Natomiast zmienne było natężenie uzależnione od prędkości podawania i długości wolnego wylotu.

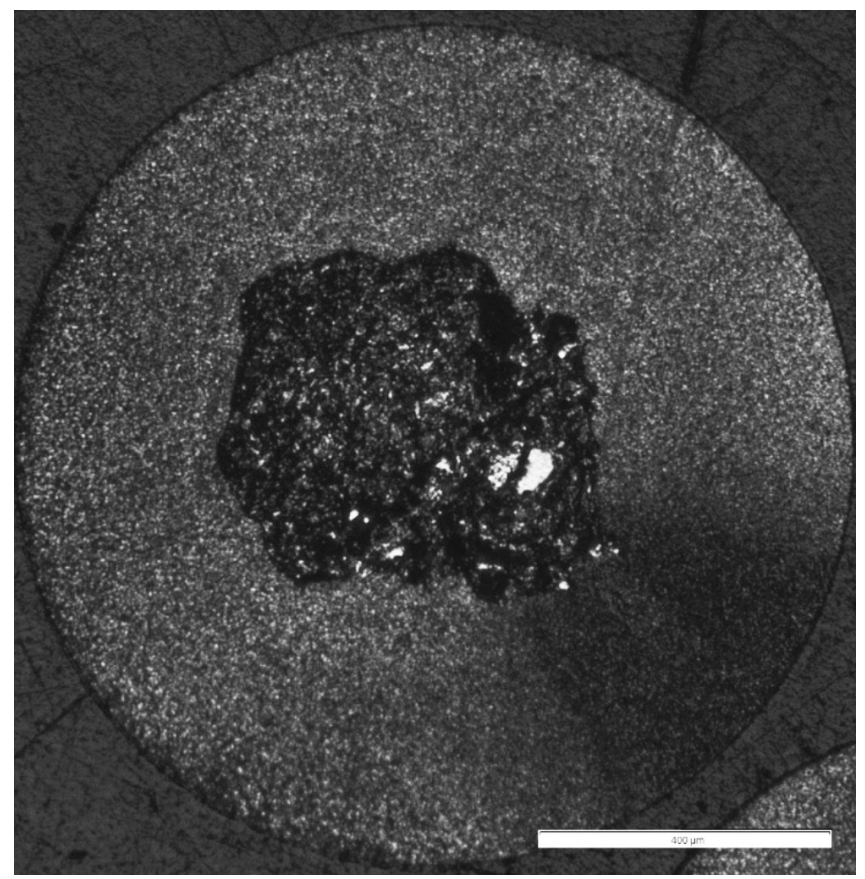

Rys. 1. Przekrój poprzeczny drutu proszkowego metalicznego o współczynniku wypełnienia $17 \%$

Fig. 1. Cross section of metal cored electrode with a fill ratio of $17 \%$

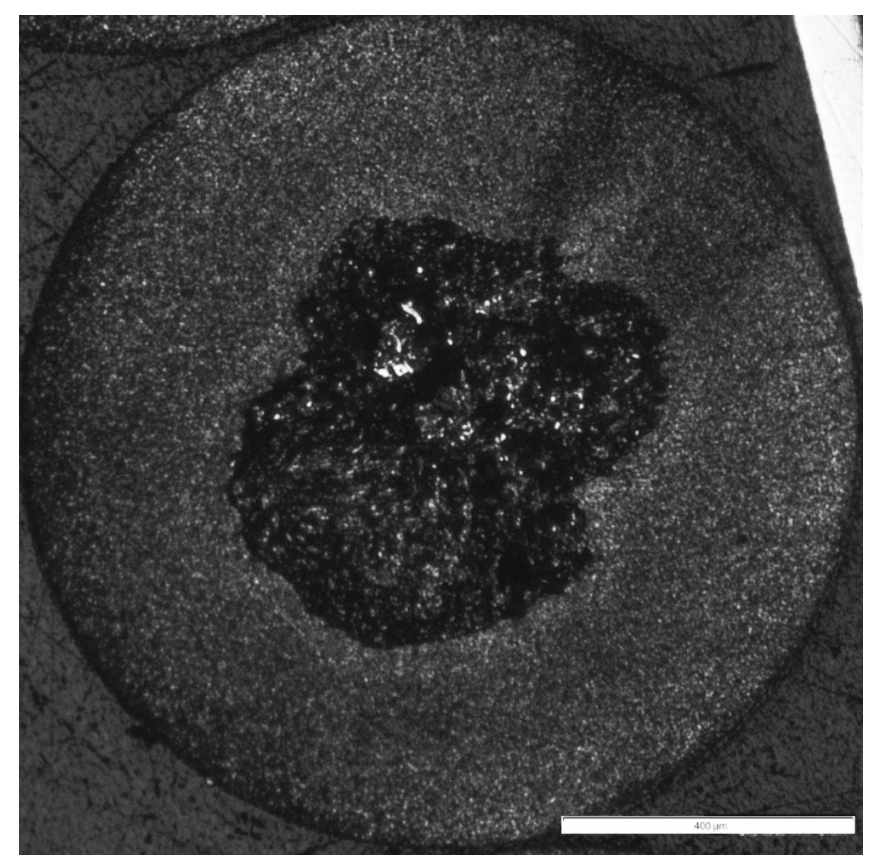

Rys. 2. Przekrój poprzeczny drutu proszkowego metalicznego o współczynniku wypełnienia $20 \%$

Fig. 2. Cross section of metal cored electrode with a fill ratio of $20 \%$

W badaniach stabilności przebiegu procesu spawania zastosowano system pomiarowy, który znajduje się na rysunku 3 Układ składa się z zasilacza, napięciowego adaptera spawania, przewodów oraz przetwornika A/C i oscyloskopu cyfrowego, które razem tworzą Weld Scanner - HKS - P1000. Przy jego wykorzystaniu istnieje możliwość rejestracji parametrów procesu spawania w czasie rzeczywistym. Zebrane dane są wyświetlane w formie charakterystyk dynamicznych. 


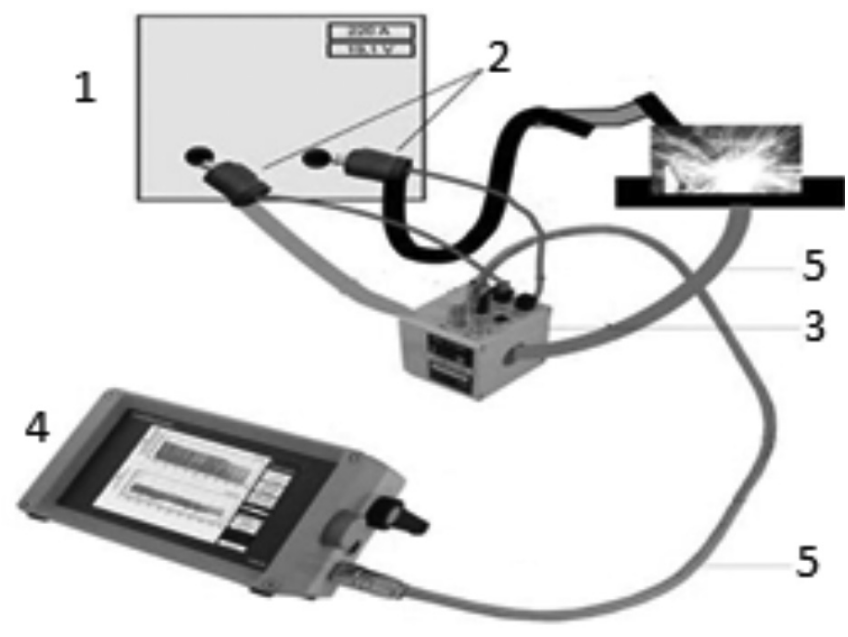

Rys. 3. Schemat stanowiska pomiarowego: zasilacz (1), napięciowy adapter spawania (2), przetwornik A/C (3), oscyloskop cyfrowy (4) oraz przewody (5) [6]

Fig. 3. The scheme of the stand-up of the measurement, consisting of a power source (1), welding voltage adapter (2), proces-sensor (3), digital oscilloscope (4) and the wires (5) [6]

Badania stabilności jarzenia łuku wykonano w pozycji PA przy dwóch wartościach natężenia prądu odpowiednio: 152 A i napięciu $18 \mathrm{~V}$ oraz $369 \mathrm{~A}$ i napięciu $37 \mathrm{~V}$. Wykorzystano źródło prądu Elektromig 450 CRW i podajnik drutu DV-4W oraz użyto osłony gazowej M21 $\left(\mathrm{Ar}+18 \% \mathrm{CO}_{2}\right)$. Długość łuku w obu przypadkach była taka sama.

\section{Wyniki}

Prędkość podawania drutów jest bezpośrednio związana $z$ natężeniem prądu. Im prędkość podawania drutu jest wyższa, tym natężenie prądu jest wyższe. Dla natężenia prądu do wartości ok. 275 A (rys. 4), druty proszkowe o współczynniku wypełnienia $20 \%$ są bardziej wydajne.

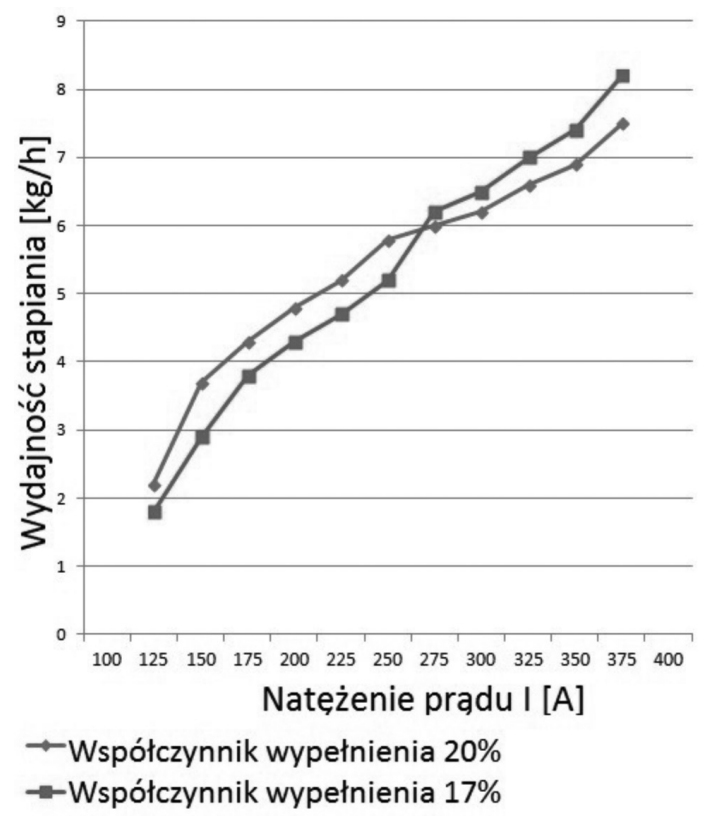

Rys. 4. Zależność wydajności stapiania drutu proszkowego od natężenia prądu dla drutów proszkowych metalicznych o współczynniku wypełnienia 17 i $20 \%$

Fig. 4. Correlation of the welding efficiency $[\mathrm{kg} / \mathrm{h}]$ as a function of welding current $[\mathrm{A}]$ for the metal cored electrode with fill ratio of 17 and $20 \%$
W przypadku, gdy natężenie wynosi 275 A wydajność obu rodzajów drutów jest taka sama. W przypadku drutów proszkowych o niższym współczynniku wypełnienia (czyli o mniejszej gęstości prądu przewodzonego przez rurkę metalową) powyżej natężenia około $275 \mathrm{~A}$, charakter transferu prądu przez rurkę metalową będzie taki sam jak dotychczasowo. Natomiast, w przypadku drutów proszkowych o wyższym współczynniku wypełnienia, gęstość prądu (przy tej samej prędkości podawania co w przypadku drutów proszkowych o niższym współczynniku wypełnienia) będzie tak wysoka, że zaczną się one stapiać jak druty lite. Wówczas ich wydajność spadnie, a proces spawania będzie zachodził niestabilnie. Na rysunku 4 przedstawiono zależność zmiany wydajności stapiania drutem proszkowym metalicznym dla drutu gatunku EN ISO 17632-A-T 466 M M 1 H5 w funkcji natężenia prądu spawania.

Zależności natężenia prądu w funkcji czasu przedstawiono na rysunkach $5 \div 8$. Wartości natężenia prądu zostały dobrane w oparciu o wykres (rys. 4), tak aby odpowiadały zakresom poniżej i powyżej natężenia $275 \mathrm{~A}$.

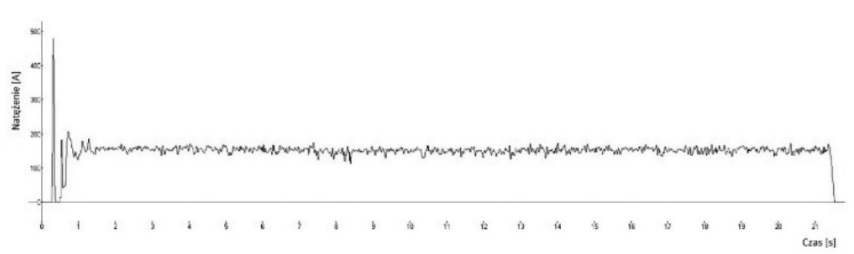

Rys. 5. Wartości natężenia prądu I=153 A w funkcji czasu dla spawania drutem proszkowym metalicznym o współczynniku wypełnienia $20 \%$ Fig. 5. Currents value $(I=153 \mathrm{~A})$ in time for a metal cored electrode with fill ratio of $20 \%$

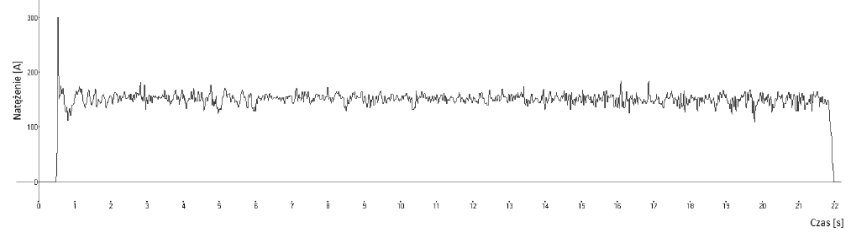

Rys. 6. Wartości natężenia prądu I=152 A w funkcji czasu dla spawania drutem proszkowym metalicznym o współczynniku wypełnienia $17 \%$

Fig. 6. Currents value $(I=152 \mathrm{~A})$ in time for a metal cored electrode with fill ratio of $17 \%$

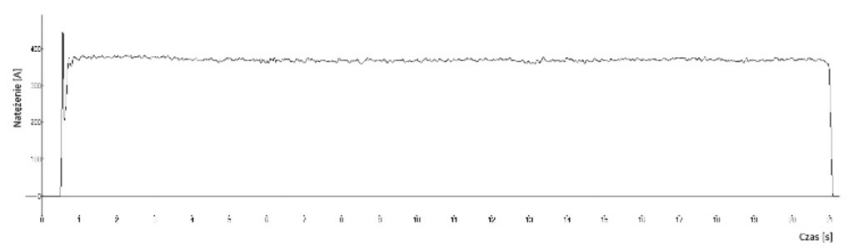

Rys. 7. Wartość natężenia prądu I=370 A w funkcji czasu dla spawania drutem proszkowym metalicznym o współczynniku wypełnienia $17 \%$

Fig. 7. Currents value $(I=370 \mathrm{~A})$ in time for a metal cored electrode with fill ratio of $17 \%$

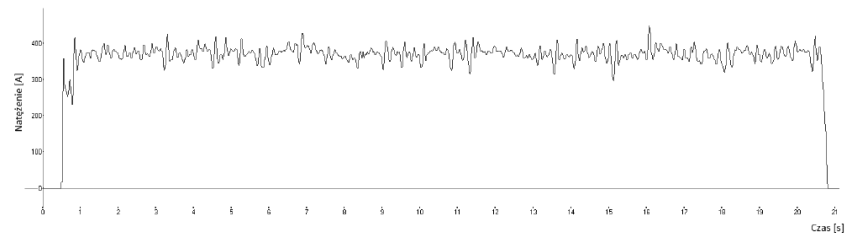

Rys. 8. Wartość natężenia prądu I=369 A w funkcji czasu dla spawania drutem proszkowym metalicznym o współczynniku wypełnienia $20 \%$

Fig. 8. Currents value $(\mathrm{I}=369 \mathrm{~A})$ in time for a metal cored electrode with fill ratio of $20 \%$ 
Dla natężenia 153 A, łuk przy spawaniu drutem proszkowym metalicznym o współczynniku wypełnienia $20 \%$ jarzy się stabilnie (rys. 5). Natomiast drut o niższym współczynniku wypełnienia jarzy się mniej stabilnie (rys. 6). Dodatkowo na podstawie procedur wewnętrznych zakładu [7], bazujących na odchyleniu standardowym wartości natężenia prądu, można określić charakter przebiegu procesu spawania. Dla wartości odchylenia standardowego poniżej 10, proces przebiega stabilnie, a powyżej niestabilnie. Odchylenie standardowe natężenia prądu dla drutu o współczynniku wypełnienia $20 \%$ wynosiło 7,3 , a dla drutu o współczynniku wypełnienia $17 \%$ odchylenie standardowe wyniosło 16,2 .

Analogiczny przypadek zaobserwowano podczas spawania przy wyższych parametrach natężenia prądu wyno-

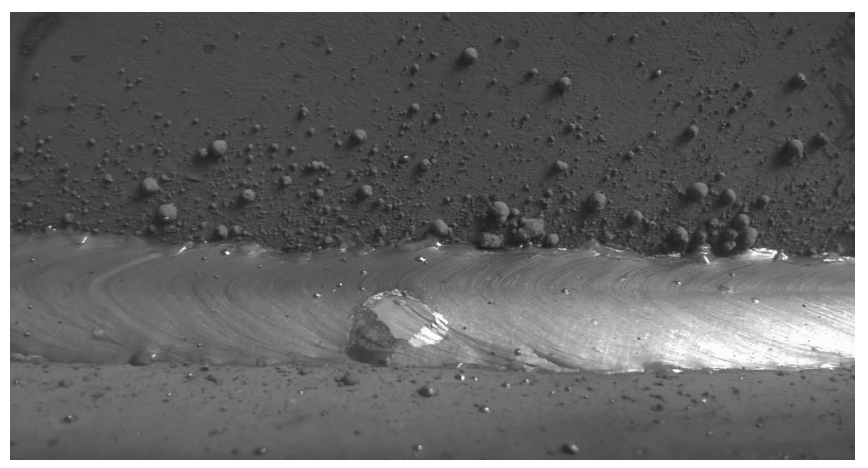

Rys. 9. Złącze spawane z licznymi rozpryskami wykonane drutem o współczynniku wypełnienia $20 \%$

Fig. 9. Welded joint with many spatters (metal cored electrode with fill ratio $20 \%$ ) szących 370 A. Łuk dla drutu o współczynniku wypełnienia $17 \%$ jarzył się stabilnie (rys. 7), w przeciwieństwie do drutu o wyższym współczynniku wypełnienia (rys. 8). Niestabilność procesu jest zilustrowana na wykresach przez liczne fluktuacje krzywej, której zmienność jest widoczna w stosunku do krzywej obrazującej stabilność procesu. Odchylenie standardowe natężenia prądu dla drutu o współczynniku wypełnienia $20 \%$ wynosiło 19 , a dla drutu o współczynniku wypełnienia $17 \%$ odchylenie standardowe wyniosło 4,3 . W wyniku spawania drutem proszkowym metalicznym o współczynniku wypełnienia $20 \%$, wokół spoiny występowało wiele rozprysków (rys. 9). Natomiast przy spawaniu drutem o współczynniku wypełnia 17\%, ilość rozprysków była znikoma (rys. 10).

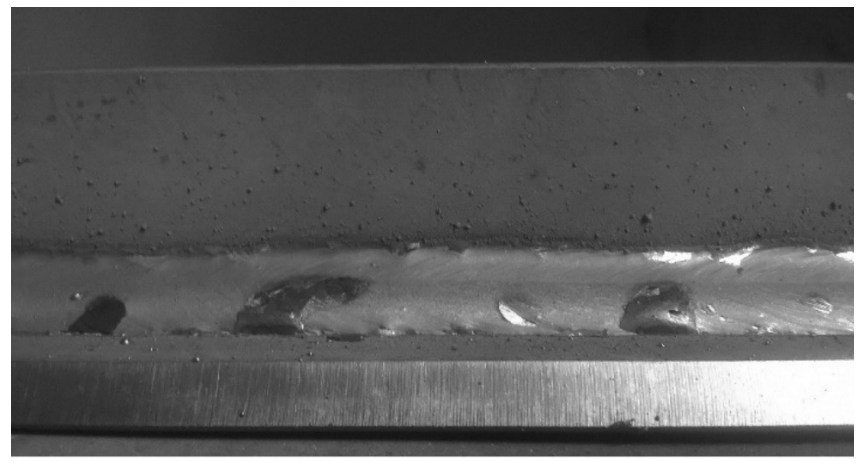

Rys. 10. Złącze spawane z licznymi odpryskami wykonane drutem o współczynniku wypełnienia $17 \%$

Fig. 10. Welded joint with few spatters (metal cored electrode with fill ratio $17 \%)$

\section{Wnioski}

Przeprowadzone badania pozwoliły na określenie wpływu współczynnika wypełnienia drutów proszkowych metalicznych na stabilność jarzenia się łuku. Podczas spawania drutami o wyższym współczynniku wypełnienia, przy niższych wartościach natężenia prądu, proces spawania przebiega stabilnie. Wydajność stapiania tych drutów jest wyższa w porównaniu z drutami o niższym współczynniku. Potwierdzeniem są wykonane analizy zmiany natężenia prądu w funkcji czasu, zestawione na wykresach (rys. $5 \div 8$ ). Dodatkowo wynika to z wyższej gęstości prądu przewodzonego przez koszulkę rurkową drutu o wyższym współczynniku wypełnienia. Dla badanych drutów określono wartość natężenia prądu spawania, dla której wydajność stapiania jest taka sama i wnosi około 275 A. W przypadku spawania drutami proszkowymi o wyższym współczynniku wypełnienia, przy wyższej wartości natężenia prądu, proces przebiega niestabilnie. Wynika to z charakteru przewodzenia prądu przez drut proszkowy metaliczny oraz zależności kształtowo-wymiarowych spoiny. Nieprawidłowy dobór parametrów determinuje pojawienie się znacznej ilości rozprysków oraz mniejszą ilość ciekłego metalu transferowanego do jeziorka tworzącego spoinę.

W słowie zakończenia należy dodać, że praca powstała we współpracy firmy Multimet Sp. z o.o. i Politechniki Wrocławskiej. Multimet Sp. z o.o. jest doświadczonym i wiodącym producentem materiałów spawalniczych w tym również bezszwowych drutów proszkowych. Wspólnie z Politechniką Wrocławską przeprowadzono cykl testów obrazujących zależność pomiędzy charakterystyką techniczną drutów proszkowych, a parametrami procesu.

\section{Literatura}

[1] R. Bęczkowski, M. Gucwa: Możliwość zastosowania napawania drutem rdzeniowym z wykorzystaniem prądu pulsującego, Przegląd Spawalnictwa, vol. 87, s. 13-16, 2015.

[2] R. Bęczkowski, M. Gucwa: Wpływ parametrów napawania drutem z rdzeniem metalicznym na wydajność procesu i parametry geometryczne ściegu, Przegląd Spawalnictwa, vol. 88, s. 49-52, 2016.

[3] E. Tasak:, Metalurgia spawania, Wydawnictwo JAK, Kraków 2008
[4] J. Pilarczyk: Poradnik inżyniera. Spawalnictwo T. 2, Wydawnictwa Naukowo-Techniczne, Warszawa 2005.

[5] M. Fidali, B. Ślązak: Zastosowanie krótko-czasowej transformaty Fouriera do analizy procesu spawania elektrodą otuloną, Przegląd Spawalnictwa, vol. 87, s. 115-120, 2015.

[6] http://www.hks-prozesstechnik.de

[7] Multimet Sp. z o.o. 